\title{
DERECHO A LA SALUD INTRAMUROS
}

\section{INTRAMURAL RIGHT TO HEALTH}

\author{
Nadia Virginia Copello' \\ DOI: https://doi.org/10.37767/2591-3476(2020)32 \\ Comentario a \\ Minnicelli, Claudio s/recurso de casación \\ Cámara Federal de Casación Penal
}

(Poder Judicial de la Nación)

\author{
Disponible en \\ https://bit.ly/3g9cTTD
}

\section{RESUMEN:}

Un hombre, con un estado de salud delicado, se encontraba detenido en un establecimiento penitenciario. A partir de informes médicos advierten que su patología requiere de un tratamiento que no puede llevarse a cabo, en condiciones óptimas, dentro de la unidad carcelaria. Lo que motivó a la defensa técnica del detenido a solicitar un arresto domiciliario.

Este contexto, nos conduce al análisis de las personas privadas de libertad como sujetos de derechos, el derecho a una atención integral de salud, tanto como a las condiciones carcelarias dignas.

Asimismo, surgen dos cuestiones relevantes. Por un lado, el habeas corpus como el mecanismo mediante el cual se pretende subsanar cualquier situación que implique un agravamiento en las condiciones de detención. Por otro, la entrada en vigencia de normas del nuevo Código Procesal Penal Federal.

Por último, será necesario reflexionar sobre el contraste de las normas y la realidad carcelaria.

\begin{abstract}
A man, in a delicate state of health, was detained in a prison facility. From medical reports, they warn that their pathology requires treatment that cannot be carried out, in optimal conditions, within the prison unit. This motivated the technical defense of the detainee to request a house arrest.

This context leads us to the analysis of people deprived of liberty as subjects of rights, the right to comprehensive health care, as well as dignified prison conditions.

Also, two relevant issues arise. On the one hand, habeas corpus as the mechanism by which it is intended to correct any situation that implies an aggravation of the conditions of detention. On the other, the entry into force of regulations of the new Federal Criminal Procedure Code. Finally, it will be necessary to reflect on the contrast of the rules and the prison reality.
\end{abstract}

1 Abogada, Universidad Nacional de Córdoba. Auxiliar Administrativa de la Defensoría Pública Oficial ante los Tribunales Federales de Primera y Segunda Instancia de Córdoba. Estudiante del Profesorado en Ciencias Jurídicas y adscripta de la cátedra de Derecho Procesal Penal, ambas de la Facultad de Derecho de la Universidad Nacional de Córdoba. Mail: copellonadiav@gmail.com - ORCID iD: https://orcid.org/0000-0001-9557-107 
PALABRAS CLAVE: Derecho a la salud; personas privadas de libertad; trato digno; prisión domiciliaria; habeas corpus.

KEY WORDS: Right to health; persons deprived of liberty; dignified treatment; home prison; habeas corpus.

\section{Introducción}

Un hombre de 54 años de edad -C.M.-, detenido en el Complejo Penitenciario Federal II de Marcos Paz, mediante sus defensores solicitó, en abril del año 2019, el cambio de la medida de restricción de su libertad a una prisión domiciliaria, fundamentándose en su delicado estado de salud. Según los informes médicos este hombre tenía antecedentes de hipertensión arterial, dislipemia, tabaquismo, cardiopatía coronaria, con precedente de infarto agudo de miocardio y otras afecciones cardíacas, que requieren de una especial atención médica.

Inicialmente, ante la afección cardiovascular mencionada, se presentó un pedido de prisión domiciliaria, dado que resultaba controvertido si la Unidad Penitenciaria donde se encontraba alojado el imputado contaba con la infraestructura necesaria para dar tratamiento a esa patología. Corrida la vista a las partes y habiendo analizado los informes del Cuerpo Médico Forense y del Director del Hospital Central del Complejo Penitenciario Federal II, el Tribunal Oral en lo Penal Económico ordena el traslado del detenido a la Unidad Penitenciaria $N^{\circ} 31$, donde podrían cumplir con las recomendaciones médicas.

El traslado se efectivizó, aun mediando oposición del propio C.M. Motivo por el cual, interpuso un habeas corpus ante el Juzgado Federal en lo Criminal y Correccional № 2 de Lomas de Zamora. Esto originó una revisión de los requerimientos necesarios para atender adecuadamente la salud de C.M.

De este nuevo análisis, surgen dos recomendaciones del dictamen de los peritos forenses que no podían ser atendidas intramuros, a saber: la rehabilitación cardiovascular bajo la supervisión permanente de un cardiólogo y con aparatología específica; y, la derivación directa a un centro de alta complejidad frente a una eventual crisis cardíaca del imputado.

Pese a estas consideraciones, el 12 de septiembre de 2019, el Tribunal Oral no hizo lugar al arresto domiciliario. Decisión que fue impugnada mediante recurso de casación.

La Sala I de la Cámara Federal de Casación Penal, en diciembre de 2019, por mayoría decidió hacer lugar al recurso y anular la decisión que rechazó el pedido de prisión domiciliaria a fin de que se dicte una nueva resolución que tuviera en cuenta debidamente no sólo los informes médicos, sino además el cambio de paradigma respecto de la libertad durante el proceso, que operó con la entrada en vigencia de los artículos del Nuevo Código Procesal Penal Federal.

Al respecto, cabe recordar la sanción de la Ley $N^{\circ} 27.063$, del nuevo régimen procesal en materia penal federal, es de implementación progresiva. Tal es así que, mediante la Resolución N²/2019 de fecha 13 de noviembre de 2019, se dispuso la puesta en marcha de diversas normas, entre ellas los artículos 210, 221 y 222, que regulan lo referido al resguardo de la libertad del imputado en el marco del proceso penal. 
Resulta de interés el voto de la segunda jueza, la Dra. Ana María Figueroa, quien se inclinó por hacer lugar al pedido de prisión domiciliaria. En su voto hizo una valoración de esta medida alternativa, teniendo especialmente en cuenta la incidencia del encierro en la salud de las personas y la obligación del Estado argentino de salvaguardar los derechos de las personas privadas de su libertad.

\section{La salud como valor constitucional supremo.}

La Organización Mundial de la Salud, en su Carta Constitutiva, expresa que "La salud es un estado de completo bienestar físico, mental y social, y no solamente la ausencia de afecciones o enfermedades" . Así concebida, la salud es catalogada como un derecho humano fundamental "sin distinción de raza, religión, ideología política o condición económica o social." ${ }^{3}$

En el sistema normativo argentino, hasta antes de la reforma de 1994, el derecho a la salud encontraba recepción en el artículo 33 de la Constitución Nacional como derecho no enumerado. A partir de la citada reforma, mediante la incorporación de Tratados Internacionales de Derechos Humanos a la Carta Magna (artículo 75, inciso 22), se le otorgó jerarquía supralegal y constitucional a los derechos en ellos reconocidos.

A modo de ejemplo, el artículo 11 de la Declaración Americana de Derechos y Deberes del Hombre de 1948, establece que "toda persona tiene derecho a que su salud sea preservada por medidas sanitarias y sociales, relativas a la alimentación, el vestido, la vivienda y la asistencia médica, correspondientes al nivel que permitan los recursos públicos y los de la comunidad." ${ }^{\text {" }}$

Ahora bien, en el caso bajo estudio, además debemos tener en cuenta los derechos que tienen las personas privadas de libertad, que tienen origen a partir de esta condición de encierro. El propio texto constitucional, en su artículo 18 in fine, dispone "las cárceles de la Nación serán sanas y limpias para seguridad y no para castigo de los reos y detenidos en ellas (....)."5 Esto es conocido como el principio de humanidad en la ejecución de las penas, como pauta fundamental en el marco del sistema carcelario.

En este sentido, se ha adoptado un conjunto de garantías de las personas frente a la persecución penal del Estado y los límites a los que queda sometido el Estado. Posteriormente, se llevó a cabo un proceso de humanización de la pena a través de la jerarquización de los tratados de derechos humanos, reforzando aquella enunciación del artículo 18.

Al respecto, Marcos Gabriel Salt (2005) entiende que "el constituyente estableció de manera precisa el principio de humanidad en la ejecución de las medidas privativas de la libertad que debe regir como pauta de orientación de toda la actividad de los órganos del Estado que intervienen en la ejecución".6

\section{Derecho a condiciones carcelarias dignas.}

Ahora bien, este derecho a la salud como valor constitucional supremo, tiene especial

\footnotetext{
2 Organización Mundial de la Salud (2006): Constitución de la Organización Mundial de la Salud. (https://www.who.int/governance/eb/who_constitution_ sp.pdf?ua=1) (Fecha de consulta: 13 de mayo de 2020).

3 Organización Mundial de la Salud (2006): Op. Cit. (Nota Nº2).

4 INFOLeg, Información Legislativa y Documental (2020): Declaración Americana de Derechos y Deberes del Hombre (http://www.infoleg.gob.ar/?page_ id=1000) (Fecha de consulta: 13 de mayo de 2020).

5 INFOLeg, Información Legislativa (2020): Constitución de la Nación Argentina. (http://servicios.infoleg.gob.ar/infolegInternet/anexos/0-4999/804/norma. htm) (Fecha de consulta: 13 de mayo de 2020).

6 RIVERA BEIRAS, Iñaki y SALT, Marcos Gabriel (2005): Los derechos fundamentales de los reclusos. España y Argentina, Buenos Aires, Del Puerto, p. 155.
} 
importancia cuando estamos frente a personas privadas de libertad. Previo a todo, es menester, concebir a las personas privadas de libertad como sujetos de derechos. La aclaración resulta necesaria porque existe una creencia social de que la cárcel es un "castigo merecido", de allí que el Estado "pueda" limitar otros derechos de los presos.

Esta referencia no es aleatoria, sino que además de la falta de conciencia generalizada de los derechos que le asisten a estas personas, sucede que en la práctica ese contexto de encierro implica algo más que la pérdida de su libertad ambulatoria.

Hoy la situación de superpoblación carcelaria provoca un deterioro de las condiciones de detención que constituyen un evidente vulneración de las garantías a un trato digno y a condiciones carcelarias adecuadas, previstas a nivel constitucional y en los pactos internacionales de derechos humanos.

En este marco, el Estado debe "garantizar a las personas privadas de la libertad condiciones carcelarias dignas. Antes bien, (...) el alojamiento de los internos en condiciones carcelarias inadecuadas deviene el encierro carcelario en ilegítimo (... )".?

Este derecho a condiciones carcelarias dignas y la prohibición de penas o tratos inhumanos o degradantes encuentra expresa recepción legal en el artículo 72 inciso 22 de nuestra Constitución Nacional, a través de la regulación de pactos internacionales, a saber: artículo 5 de la Convención Americana sobre Derechos Humanos; artículos 7 y 10, apartado 1, del Pacto Internacional de Derechos Civiles y Políticos; y los artículos 2 y 16 de la Convención contra la Tortura y Otros Tratos o Penas Crueles, Inhumanos y Degradantes..

Esta enunciación no es una mera declaración de principios o derechos, sino que estamos frente a una obligación constitucional del Estado de "brindar a las personas que priva de libertad determinadas condiciones de trato que, de no cumplirse, tornan al encierro ilegítimo". ${ }^{8}$

Así, uno de los derechos que debe garantizar el Estado dentro de los establecimientos penitenciarios es el derecho a salud y asistencia sanitaria, derecho que se encuentra vinculado con la integridad psicofísica de las personas y que se presenta "(...) como valor constitucional supremo(...). ${ }^{\prime 9}$

Retomando la idea de las personas privadas de libertad como sujetos de derecho, el artículo 2 de la Ley $\mathrm{N}^{\circ} 24.660$, de Ejecución de la Pena Privativa de la Libertad, establece para su aplicación, el principio constitucional de reserva, el que dispone que el preso "podrá ejercer todos los derechos no afectados por la condena o por la ley y las reglamentaciones que en su consecuencia se dicten y cumplirá con todos los deberes que su situación le permita y con todas las obligaciones que su condición legalmente le impone. "mo

En la misma línea de análisis, también identificamos el principio de legalidad -nulla poena sine lege-, y a partir de allí podemos afirmar que "el interno es un sujeto de derechos que como regla general, será titular de los mismos que las personas libres y, como excepción,

\footnotetext{
7 ROUTOLO, Marco (2004): Derechos de los Detenidos y Constitución, Buenos Aires, Ad Hoc, p. 31. 8 RIVERA BEIRAS, Iñaki y SALT, Marcos Gabriel (2005): Op.Cit. p.214.

9 ROUTOLO, Marco (2004): Ob.Cit., p. 210.

10 INFOLeg, Información Legislativa (2020): Ley de Ejecución de la Pena Privativa de la Libertad, Ley 24.660. (http://servicios.infoleg.gob.ar/infolegInternet/ anexos/35000-39999/37872/texact.htm) (Fecha de consulta: 11 de mayo de 2020).
} 
sufrirá limitaciones especialmente previstas en el ordenamiento jurídico como inherentes a la resolución judicial que dispuso la medida de encierro carcelario. ${ }^{m 1}$

\section{Derecho a la salud intramuros.}

La citada Ley 24.660 regula diferentes aspectos relacionados al tratamiento penitenciario. En lo que aquí interesa, en el capítulo III de normas de trato, en lo referido a la higiene de los internos dispone que "El régimen penitenciario deberá asegurar y promover el bienestar psicofísico de los internos. Para ello se implementarán medidas de prevención, recuperación y rehabilitación de la salud y se atenderán especialmente las condiciones ambientales e higiénicas de los establecimientos. ${ }^{\text {"2 } 2}$

A la vez que, en relación a la asistencia médica el artículo 143 prevé que "El interno tiene derecho a la salud. Deberá brindarsele oportuna asistencia médica integral, no pudiendo ser interferida su accesibilidad a la consulta y a los tratamientos prescriptos. Los estudios diagnósticos, tratamientos y medicamentos indicados, le serán suministrados sin cargo."m3

Las personas privadas de libertad tienen el mismo derecho a la salud que las personas en libertad. Sin embargo, las primeras "no sólo poseen los mismos factores de riesgo para desarrollar enfermedades (...), sino que además éstos se ven incrementados por el contexto de encierro y la falta de libertad." ${ }^{\prime 4}$

Esta asistencia médica integral es un deber del Estado, quien deberá articular con las autoridades de los servicios penitenciarios, políticas de sanidad a fin de garantizar su efectivo cumplimiento.

Es necesario compatibilizar las medidas de seguridad que requieren estos establecimientos con las condiciones del servicio sanitario penitenciario. Así "la legitimidad de las limitaciones que derivan de las exigencias de seguridad, será puesta en discusión allí donde ellas se impongan o pretendan imponerse en modo suficiente para menoscabar el núcleo irreductible del derecho a la salud protegido por la Constitución." ${ }^{\prime 5}$

En práctica, muchas veces se utiliza el argumento económico a fin de justificar el incumplimiento de las exigencias de un trato digno, presentándose como una de las tantas formas de violación de la dignidad humana.

La doctrina se ha expresado sobre este punto y considera que "Ias exigencias financieras no pueden legitimar una compresión del núcleo irreductible del derecho a la salud, protegido por la Constitución como ámbito inviolable de la dignidad humana." ${ }^{\text {"n }}$

La sobrepoblación y hacinamiento carcelario provoca un factor determinante en la salud de los detenidos, de allí que sea necesario dar prioridad al servicio sanitario en la agenda de discusión política.

\footnotetext{
11 RIVERA BEIRAS, Iñaki y SALT, Marcos Gabriel (2005): Op.Cit. p.178.

12 INFOLeg, Información Legislativa (2020): Ob. Cit. (Nota $\left.\mathrm{N}^{\circ} 10\right)$.

13 INFOLeg, Información Legislativa (2020): Ob. Cit. (Nota $\left.\mathrm{N}^{\circ} 10\right)$

14 GIORGI, Salvador; KOHAN, Pablo; KREPLAK, Nicolás y LARRABIDE, Joaquín (2013): Atención y Cuidado de la Salud de Personas Privadas de su Libertad, Ciudad Autónoma de Buenos Aires, Ministerio de Justicia y Derechos Humanos de la Nación, p. 6 (http://www.saij.gob.ar/docs-f/ediciones/libros/atencion_ personas_privadas_libertad.pdf) (Fecha de consulta: 11 de mayo de 2020.

15 ROUTOLO, Marco (2004): Ob.Cit., p. 213.

16 ROUTOLO, Marco (2004): Ob.Cit., p. 211.
} 


\section{Prisión domiciliaria como medida alternativa.}

Ahora bien, ¿qué sucede cuando existe una incompatibilidad entre un tratamiento médico adecuado y la detención? Es decir, cuando el tratamiento no puede ser llevado a cabo en óptimas condiciones intramuros o cuando la patología del interno pueda afectar la salud de otros detenidos.

Existe una salida alternativa que permitiría conciliar los intereses en juego y es el instituto de la prisión domiciliaria. En líneas generales, consiste en la privación de la libertad del detenido en su domicilio o en uno diferente dispuesto por el juez.

El arresto domiciliario tiene lugar ante ciertas hipótesis enumeradas en la ley. El artículo 10, inciso "a" del Código Penal Argentino le otorga al juez la facultad de disponer esta medida cuando "(...) la privación de la libertad en el establecimiento carcelario le impide recuperarse o tratar adecuadamente su dolencia y no correspondiere su alojamiento en un establecimiento hospitalario (...)"..17 Por su parte, la Ley Ejecución de la Pena Privativa de la Libertad en su artículo 32 hace remisión expresa a lo dispuesto por el código de fondo.

En el caso bajo análisis, C.M. presentaba un cuadro clínico complejo que exigía ciertas precauciones: la rehabilitación cardiovascular bajo la supervisión permanente de un cardiólogo y con aparatología específica; $y$, la derivación directa a un centro de alta complejidad frente a una eventual crisis cardíaca del imputado.

Esta circunstancia justificó la petición de prisión domiciliaria efectuado por su defensa, dado que estas recomendaciones médicas no podían llevarse a cabo de manera adecuada en el establecimiento carcelario.

Se debe tener presente que la prisión domiciliaria continua siendo una situación de privación de libertad, pero morigerada. En los hechos, es necesario considerar que la concesión o no del recurso pone en juego el derecho a la salud y el de la vida de C.M, por lo que debería analizarse cuánto repercute en ellas, el encierro y las dificultades en su atención por parte del servicio penitenciario.

En este sentido, sostener una decisión adversa agravaría las condiciones de detención de C.M. y esto constituiría, según lo que venimos analizando, un "trato inhumano y degradante, que compromete las obligaciones internacionales asumidas por el Estado Nacional y viola las garantías constitucionales (... $)^{m 8}$.

La jurisprudencia argentina es conteste en este sentido y ha expresado en variadas resoluciones que "(...) la razón de ser del instituto de la prisión domiciliaria, consiste en evitar que el encierro carcelario produzca un agravamiento de las condiciones personales de quienes se encuentra en prisión, más allá de lo que la propia privación de la libertad implica"mi.

\section{Norma vs. realidad.}

La normativa es clara: el legislador ha enunciado un catálogo de derechos de las personas privadas de libertad. Sin embargo, las cárceles se erigen como uno de los lugares

\footnotetext{
17 INFOLeg, Información Legislativa (2020): Código Penal de la Nación Argentina, Ley 11.179 (T.O. 1984 actualizado. (http://servicios.infoleg.gob.ar/ infolegInternet/anexos/15000-19999/16546/texact.htm) (Fecha de consulta: 11 de mayo de 2020).

18 "PLA". Causa № 2579/2012. Cámara Federal de Casación Penal, Sala IV (7/9/2017)

19 “BAH”, Reg. № 730/17. Causa Nº314/2013. Cámara Federal de Casación Penal, Sala II (15/6/2017).
} 
más crueles y deshumanizados y como centros de diferentes formas de violación de la dignidad de las personas.

Tal es así que, si una persona no conociera la realidad carcelaria y "le damos para que lea el texto de una ley de ejecución en cualquiera de nuestros países, seguramente tendrá una idea errada sobre cuál es el estado de las cárceles y el status jurídico de las personas privadas de la libertad. Lo que sucede en realidad es que la cárcel es uno de los ámbitos de la relación Estado - ciudadano en el que se manifiesta de manera más evidente la desconexión entre la ley y la realidad carcelaria." 20

Para el mejoramiento del sistema carcelario es necesario acortar las brechas de este contraste entre norma y realidad. Requiere de un cambio en la política criminal del Estado y entender a las personas privadas de libertad como sujetos de derechos.

En esta tarea de profundizar en los derechos y de crear mecanismos jurídicos para garantizar la seguridad jurídica de los detenidos, el legislador ha creado el instituto del habeas corpus mediante la Ley $N^{\circ} 23.098$ de Procedimiento de Habeas Corpus -anterior a la reforma de 1994-.

La Constitución Nacional prevé en el último párrafo del artículo 43 que "Cuando el derecho lesionado, restringido, alterado o amenazado fuera la libertad física, o en caso de agravamiento ilegítimo en la forma o condiciones de detención, o en el de desaparición forzada de personas, la acción de habeas corpus podrá ser interpuesta por el afectado o por cualquiera en su favor y el juez resolverá de inmediato, aun durante la vigencia del estado de sitio."21

Se trata de un herramienta rápida y desprovista de formalidades que se emplea a fin de "subsanar, con intervención judicial, el agravamiento ilegítimo de una privación de libertad."22. En el caso particular, C.M. no podía ser atendido de manera apropiada en la unidad penitenciaria en la que se encontraba alojado, por lo que se dispuso su traslado a otro establecimiento -en donde tampoco podrían cumplir las recomendaciones médicas de manera adecuada-. Frente a ello, C.M. se opuso expresamente, y aun mediando esta oposición, se efectuó el traslado. Este cambio de lugar de detención sin su consentimiento, agravó sus condiciones de detención, lo que justificó la presentación de un habeas corpus.

\section{Cambio de paradigma sobre las medidas de coerción penal.}

Por último, el fallo analizado trae a colación el nuevo paradigma sentado a partir de la vigencia del nuevo Código Procesal Penal Federal. La entrada en vigencia de la Ley $\mathrm{N}^{\circ}$ 27.063 se ha dispuesto de manera gradual, ya que implica profundos cambios en el procedimiento penal federal.

En diciembre de 2019 se hicieron operativos, entre otros, los artículos 210, 221 y 222 del mencionado cuerpo. Así, el artículo 210 contiene las diferentes medidas de coerción que, de manera individual o combinada, pueden ser aplicables en casos de riesgo procesal. Por su parte, los artículos 221 y 222 refieren a los peligros -peligro de fuga y peligro de entorpecimiento, respectivamente- concretos que deben verificarse para fundar la existencia del riesgo procesal que autorizaría la adopción de alguna de las medidas.

20 ROUTOLO, Marco (2004): Ob.Cit., p. 23.

21 INFOLeg, Información Legislativa (2020): Ob. Cit. (Nota $N^{\circ} 5$ ).

22 RIVERA BEIRAS, Iñaki y SALT, Marcos Gabriel (2005): Op.Cit. p.279. 
En este catálogo está previsto el arresto domiciliario como medida de coerción -artículo 210 , inciso "j"-, menos gravosa que la prisión preventiva. Es de destacar que el enunciado de estas alternativas es progresivo, por lo que la prisión sólo debería tener lugar cuando "Ias medidas anteriores no fueran suficientes para asegurar los fines indicados"23 -neutralizar los riesgos procesales-.

El éxito de esta reforma procesal "depende de la manera en que estas normas son interpretadas y aplicadas en los casos concretos, del modo en que se sistematicen con el programa constitucional y el resto de las normas del sistema, y no por su mera implementación. ${ }^{24}$

Al resolver el recurso de casación, los jueces tuvieron especialmente en cuenta la entrada en vigencia de esta normativa. Por un lado, era necesario reexaminar los informes médicos de C.M. a fin de determinar si podía ser tratado adecuadamente su diagnóstico dentro del servicio penitenciario. Y por otro, revisar la posibilidad de aplicar una medida de coerción menos gravosa para el caso concreto.

\section{Consideraciones finales.}

A partir de la difusión de los derechos humanos, es posible acceder a diferentes instrumentos nacionales e internacionales, que contienen un amplio catálogo de derechos de las personas privadas de libertad. Sin embargo, para garantizar la vigencia de sus derechos no alcanza sólo con su reconocimiento legal.

Es importante resaltar que la situación de encierro no implica sólo la pérdida de la libertad ambulatoria. El ejercicio y goce del resto de sus derechos se encuentra condicionado o limitado a lo dispuesto por las autoridades administrativas penitenciarias. De esta manera, estos derechos se reducen a una mera ficción de la realidad carcelaria.

Refuerzo la idea de que las personas privadas de libertad son sujetos de derechos y el Estado tiene el deber de garantizarlos. Tal es así que el Estado argentino debe brindar o crear las condiciones de encierro dignas y adecuadas, bajo la responsabilidad de tornar la detención en ilegítima.

En este sentido, resultan imprescindibles procesos de transparencia que revelen cuáles son las condiciones actuales de nuestras cárceles, que nos permitan hacer reflexiones sobre las realidades en las que viven los detenidos en ellas. Éstos siguen siendo personas, que como tales tienen derecho a que se les respete la dignidad humana.

Dentro de estas condiciones dignas y adecuadas, se encuentra el derecho a una atención de salud integral. La salud se ve gravemente afectada por el encierro y expuesta a mayores riesgos. Es necesario una política institucional que otorgue otra prioridad al servicio sanitario, como así también se necesita de la buena voluntad y compromiso de los agentes de salud que forman parte del mismo.

23 Sistema Argentino de Información Jurídica (2020): Código Procesal Penal Federal (T.O.2019), Ley 27.063. (http://www.saij.gob.ar/27063-nacionalcodigo-procesal-penal-federal-to-2019-Ins0006496-2019-02-07/123456789-0abc-defg-g69-46000scanyel?) (Fecha de consulta: 15 de mayo de 2020). 


\section{REFERENCIAS BIBLIOGRÁFICAS}

- “BAH", Reg. N 730/17. Causa N7314/2013. Cámara Federal de Casación Penal, Sala II (15/6/2017).

- GIORGI, Salvador; KOHAN, Pablo; KREPLAK, Nicolás y LARRABIDE, Joaquín (2013): Atención y Cuidado de la Salud de Personas Privadas de su Libertad, Ciudad Autónoma de Buenos Aires, Ministerio de Justicia y Derechos Humanos de la Nación, p. 6 (http://www.saij. gob.ar/docs-f/ediciones/libros/atencion_personas_privadas_libertad.pdf).

- INFOLeg, Información Legislativa (2020): Código Penal de la Nación Argentina, Ley 11.179 (T.O. 1984 actualizado. (http://servicios.infoleg.gob.ar/infolegInternet/anexos/15000-19999/16546/texact.htm)

- INFOLeg, Información Legislativa (2020): Constitución de la Nación Argentina. (http:// servicios.infoleg.gob.ar/infolegInternet/anexos/0-4999/804/norma.htm)

- INFOLeg, Información Legislativa y Documental (2020): Declaración Americana de Derechos y Deberes del Hombre (http://www.infoleg.gob.ar/?page_id=1000)

- INFOLeg, Información Legislativa (2020): Ley de Ejecución de la Pena Privativa de la Libertad, Ley 24.660. (http://servicios.infoleg.gob.ar/infolegInternet/anexos/35000-39999/37872/ texact.htm)

- Organización Mundial de la Salud (2006): Constitución de la Organización Mundial de la Salud. (https://www.who.int/governance/eb/who_constitution_sp.pdf?ua=1) (Fecha de consulta: 13 de mayo de 2020).

- “PLA”. Causa N²579/2012. Cámara Federal de Casación Penal, Sala IV (7/9/2017).

- RIVERA BEIRAS, Iñaki y SALT, Marcos Gabriel (2005): Los derechos fundamentales de los reclusos. España y Argentina, Buenos Aires, Del Puerto.

- ROUTOLO, Marco (2004): Derechos de los Detenidos y Constitución, Buenos Aires, Ad Hoc.

- SERGI, Natalia (2020): Nuevas formas sobre medidas de coerción implementadas en el CPFF. Referencia Jurídica e Investigación Secretaría General de Capacitación y Jurisprudencia Ministerio Público de la Defensa.

- Sistema Argentino de Información Jurídica (2020): Código Procesal Penal Federal (T.O.2019), Ley 27.063. (http://www.saij.gob.ar/27063-nacional-codigo-procesal-penal-federal-to-2019-Ins0006496-2019-02-07/123456789-0abc-defg-g69-46000scanyel?). 